\title{
A plea for a cognitive linguistics perspective on the notion of linguistic competence in the Common European Framework of Reference
}

\author{
Ariadna Strugielska - Katarzyna Piątkowska
}

DOI: 10.18355/XL.2020.13.04.04

\begin{abstract}
This paper demonstrates that although linguistic competence (LC) is an essential dimension of the Common European Framework of Reference (Council of Europe, $2001 ; 2018$ ), it is defined in an inconsistent way resulting from combining elements of formal and functional approaches. Thus, rather than interconnected, linguistic competence emerges as dichotomized and in need of an approach that could reconcile incompatibilities in the way(s) LC is characterized in the document. We propose that a cognitive linguistic perspective built on the schematic commitment is a viable approach to re-defining LC.
\end{abstract}

Key words: linguistic competence, cognitive linguistics, schematic commitment, CEFR

\section{Introduction}

Linguistic competence is one of the significant categories underlying the CEFR in that it constitutes a generic capacity which a learner needs to possess as a language user. Built upon the pillars of language and competence, linguistic aptitude is not only internally complex itself, encompassing grammatical, lexical, semantic, phonological, orthographic, and orthoepic capacities, but also closely linked to the other communicative language competences - sociolinguistic and pragmatic - and related to general and (possibly) plurilingual/pluricultural proficiencies (Council of Europe, 2018: 46). ${ }^{1}$

In an apparent attempt to reconcile formal and functional traditions, these two characteristics of LC, i.e. internal complexity and external connections, are discussed in the CEFR from a broad perspective, encompassing, among others, a "traditional" model of linguistic description (Council of Europe, 2001: 109), sociocultural and socio-constructivist theories of language learning (Council of Europe, 2018: 30), or "competence models developed in applied linguistics since the early 1980s" (Council of Europe, 2018: 130). Much as we support the Framework's endeavor to provide a maximally unified platform for negotiating linguistic theory and practice, we also argue that the way approaches and perspectives have so far been integrated is not fully motivated and leads to incongruent views upon LC, which is simultaneously defined in formal and functional terms. Building on J. R Taylor's (2014) list of features distinguishing formal and functional approaches, we associate the former with the modularity and autonomy of the language system, focus on wellformedness and a number of exclusionary fallacies (see also Langacker, 1987), including rules vs. lists, core vs. periphery, dictionaries vs. encyclopedias and highlevel (often invisible or inaudible) schemas vs. lower-level (emanating from language use) generalizations, of which typically the first element is the proper objective of formal linguistic study. A functional perspective, on the other hand, will see language as closely intertwined with, at least, cognitive, social, and pragmatic contexts, internally unified, i.e. rejecting language compartments, such as syntax, morphology or phonology, serving to convey meaning and thus focused on intelligibility. Being in

\footnotetext{
${ }^{1}$ The status of plurilingual and pluricultural competences vis-a-vis linguistic competence is not specified in the CEFR (Council of Europe, 2018: 29) and thus only a tentative link between plurilingual/pluricultural proficiency and LC is proposed.
} 
support of continua rather than oppositions, functionalists do not distinguish between regular/irregular linguistic phenomena or schemas and their instantiations. Instead, all actually occurring objects are the focus of linguistic explanation.

\section{Linguistic competence in the CEFR (2001; 2018)}

The key objective of the CEFR is to describe "what language learners have to learn to do in order to use a language for communication and what knowledge and skills they have to develop so as to be able to act effectively" (Council of Europe, 2001: 1). In order to expand their communicative competence, learners need to develop (at least) general and communicative language skills, with the latter further divided into linguistic, sociolinguistic, and pragmatic proficiencies.

Linguistic competence consists of grammatical, lexical, semantic, phonological, orthographic and orthoepic competences (Council of Europe, 2001: 108-109; 2018: 130), all of which are assumed to constitute LC defined as "knowledge of, and ability to use, the formal resources from which well-formed, meaningful messages may be assembled and formulated" (Council of Europe, 2001: 109), and which are specified as "lexical, phonological, syntactical knowledge and skills and other dimensions of language as a system, independently of the sociolinguistic value of its variations and the pragmatic functions of its realizations" (Council of Europe, 2001: 13). A modular and autonomous LC, founded upon form, correctness, and rule-generated linguistic resources, is thus concerned not with language use but with "language usage (as in 'correct usage'), [...] and knowledge of the language as a system" (Council of Europe, 2018: 138), and is firmly situated within the formal approach.

Simultaneously, however, linguistic competence is closely linked to the other communicative competences - sociolinguistic and pragmatic - as well as general knowledge and skills, all of which evolve from situated language use and are "mobilized" in and "further developed through" a particular communicative situation (Council of Europe, 2018: 29). A functional perspective also emanates from some of the descriptors in the General linguistic range since they include a number of settings and repertoires, thus linking LC to contexts of language use, or pragmatic, sociolinguistic, and general competences, and emphasize appropriateness, clarity, and precision rather than accuracy.

The two views of LC in the CEFR, i.e. formal and functional, which transpire from its theoretical background and descriptors, can also be detected, albeit to varying degrees, in the way linguistic sub-competencies: grammatical, lexical, semantic, phonological, orthographic, and orthoepic are defined in the Framework. In fact, three classes of linguistic sub-categories can be distinguished: those dominated by the formal approach, those trying to strike a balance between functional and formal perspectives, and those shifting towards the functional stance.

\section{The formal perspective}

Grammatical, orthoepic, and semantic competences are classified as those whose characterization in the CEFR is dominated by the formal approach.

Grammatical competence is interpreted as "the ability to understand and express meaning by producing and recognizing well-formed phrases and sentences," according to general rules (Council of Europe, 2001: 113). Defined via an assembly of abstract categories ((im)perfective aspect), classes (declension), processes (suppletion) and relations (government) joined to produce regular, or core, structures (Council of Europe, 2001: 113), grammatical capacity is the quintessence of a formal approach. This perspective is also visible in the set of descriptors for Grammatical accuracy, which includes generic categories of agreement, tenses, basic/complex sentence structures, highlights well-formedness and the knowledge of the language

XLinguae, Volume 13 Issue 4, October 2020, ISSN 1337-8384, ISSN 2453-711X 
system in the form of, for instance, "simple principles of word order" and makes a distinction between general grammatical patterns, or rules, and memorized phrases and "frequently used 'routines", or lists (Council of Europe, 2018: 133). Context, if any, is associated with cognition and takes the form of memorized repertoires for lower levels of proficiency and general psychological processes, such as attention, thinking in retrospect, or forward planning in the case of more advanced learners.

Orthoepic competence, defined as a skill "required to read aloud a prepared text, or to use in speech words first encountered in their written form" (Council of Europe, 2001: 117), is based on the knowledge of conventional forms, e.g. standard spelling, the phonetic alphabet or punctuation marks. The formal perspective is only slightly expanded when the learner's ability to refer to a dictionary is mentioned. Context, if mentioned, is understood as links between elements of the language system, such as implications of punctuation for pronunciation or the influence of syntagmatic strings upon resolving syntactic ambiguities (Council of Europe, 2001: 118).

Semantic competence, defined as "the learner's awareness and control of the organization of meaning" (Council of Europe, 2001: 115) is divided, much in line with the formal modularity hypothesis, into lexical, grammatical, and pragmatic. Word meaning - built on the principles of componential analysis and sense/reference or denotation/connotation distinctions - clearly fits in the formal approach by concentrating on the core vocabulary of a language defined through sets of abstract and highly-structured dictionary features as opposed to "speaker meaning" in context (Council of Europe, 2018: 139). Grammatical and pragmatic semantics are based on equally "invisible" notions, such as meanings of categories (for instance, (in)transitive), structures (e.g. clauses) and processes (for example, transposition) or logical relations of entailment or presupposition, thus highlighting the autonomy of the language system from its ecologies. Simultaneously, however, semantic competence is linked to the category of general competences through "knowledge of the world," which is "closely correlated" with vocabulary and grammar (Council of Europe, 2001: 101). Still, how this relationship can be modeled so that linguistic and encyclopedic knowledge could be integrated is not explained in the Framework.

\section{The formal-functional perspective}

While grammatical, orthoepic, and semantic competencies can be classified as dominated by the formal approach only randomly connected with elements of general knowledge, lexical and orthographic skills, seem to involve the functional focus a bit more noticeably.

Lexical competence, which consists of knowing and being able to use lexical and grammatical elements of a language (Council of Europe, 2001: 110), is divided into single- and multi-word forms. Individual linguistic items are deftly related to open or closed classes and thus taken to instantiate abstract grammatical categories of, for instance, nouns, adjectives, determiners, or conjunctions. Unlike the neatly-classified single-word items, multi-word structures, e.g. kick the bucket or Good morning!, are not linked to any underlying generalizations but form lists of irregular structures to be memorized. Those structures, however, are simultaneously closely connected to their socio-cultural contexts of use since analogical multi-word forms, or "fixed formulae", are subsumed under sociolinguistic competence, e.g. $a$ sprat to catch a mackerel, May we now come to order, please. Right. What about making a start?, (Council of Europe, 2001: 120). Socio-pragmatic influences are also noticeable among the descriptors for Vocabulary range, with early levels of proficiency referred to familiar situations and higher stages to technical and/or specialist vocabulary (Council of Europe, 2018: 132). B2-C2 levels are also associated with the increasing mastery of idiomatic expressions, collocations, connotations, and colloquialisms which, however, is not linked to any context of use 
but instead seems to come from the knowledge of the language system, "with one expression triggering another" (Council of Europe, 2018: 134). What is implied, then, is some kind of correspondence between the level of proficiency and the degree to which competence is dependent on formal vs. functional elements.

Analogically to the haphazard combination of major (formal) and minor (functional) influences, orthographic competence, mainly focusing on standard forms, e.g. letters, contracted forms or punctuation marks (Council of Europe, 2001: 117), also introduces some unsystematic references to general, pragmatic and plurilingual contexts and a blend of accuracy and intelligibility (Council of Europe, 2018: 137).

\section{The functional perspective}

The 2018 companion to the CEFR thoroughly revises phonological competence or, to be more precise, replaces the 2001 scale for Phonological control simultaneously preserving the original theoretical description of the notion, which is still "sufficiently broad to encompass more recent reflections on aspects of phonology in second/foreign language education" (Council of Europe, 2018: 134). The 2001 characterization of phonological competence involves knowledge and skills related to sound-units (phonemes and allophones) and their distinctive features (e.g. voicing), word and sentence phonetic, including word stress and prosody and, finally, phonetic reduction in the form of, for instance, strong and weak forms or assimilation (Council of Europe, 2001: 116-117). Importantly, the 2018 descriptors for Phonological control embrace all the theoretical categories introduced in the original version of the Framework and instantiated by, for instance, intonation, rhythm, word and sentence stress or speech rate. Hence, unlike previously-described competences, the only objects of linguistic description are those actually occurring in language use. A decisive departure from abstract norms and idealized models is also signaled by a shift from native-like accent to accentedness and deviation from the standard, and from accuracy to intelligibility. Learners' needs, sociolinguistic influences, and the omnipresence of context are explicitly acknowledged (Council of Europe, 2018: 134) and consistently applied in the list of descriptors (Council of Europe, 2018: 136).

While phonological proficiency is undoubtedly the most systematicallydeveloped element of LC, it concentrates on one particular type of context, i.e. plurilingual, which unfailingly occurs throughout all levels of proficiency. Paradoxically, however, this regularity leads to substantially weakening the link between phonological competence and LC. To be more precise, while pre-existing sociolinguistic and pragmatic competences are said to be exploited and developed through plurilingual proficiency, and hence involved in phonological competence, LC becomes a blurred, or unfitting, notion, replaced by some form of "metalinguistic, interlinguistic or so to speak 'hyperlinguistic' awareness" (Council of Europe, 2018: 29). In other words, a highly-consistent and convincing description of phonological proficiency shakes its place within LC but simultaneously opens ways of re-defining linguistic competence.

\section{Towards a unifying approach to $\mathrm{LC}$ in the CEFR}

The way LC is currently presented in the CEFR makes the notion unconvincing and perhaps even redundant since linguistic competence is either internally torn between formal and functional perspectives or doubted when combined with the other competencies, e.g. plurilingual.

Discussing the theoretical underpinnings of the Framework, G. Fulcher (2004) observes that such obscurity of constructs may lead to chaos, and L. Vincent (2004: 43-44) specifies that much confusion in the CEFR is generated by the way relations between competencies are defined and justified. Particular criticisms refer to a lack of coherence in considering relationships between proficiencies, which, while

XLinguae, Volume 13 Issue 4, October 2020, ISSN 1337-8384, ISSN 2453-711X 
declared to be interconnected in the Framework, are inconsistently arranged. In the light of the present discussion, similar concerns can be voiced with reference to the way sub-competencies constituting LC are linked since the arrangement proposed in the Framework clearly separates the formal sub-categories (grammatical, semantic, and orthoepic) from the functionally-interpreted phonological competence, with lexical and orthographic skills left somewhere in between. Simultaneously though, a new category - hyperlinguistic awareness - is tentatively offered in lieu of LC, and we suggest, for reasons explained below, that this notion should indeed be as a starting point for re-defining linguistic competence in the CEFR.

\section{From hyperlinguistic awareness to cognitive linguistics}

When discussing ways of combining social and cognitive elements in theories of language development, D. Larsen-Freeman (2018: 58) notes that what is at issue nowadays is not whether both are involved, since they always are, but how the formal and functional influences are related. The link that emanates from our discussion of LC in the CEFR is the construct of hyperlinguistic awareness (HA), developed through plurilingual/pluricultural encounters and defined as "a better perception of what is general and what is specific concerning the linguistic organization of different languages" (Council of Europe, 2018: 29). Evidently related to detecting commonalities between languages, HA enables thinking in superordinate categories which have been abstracted from actual language use. In a way, then, HA is similar to a supersystem, or "a minimally sorted and organized set of memories of what people have heard and repeated over a lifetime of language use, a set of forms, patterns, and practices that have arisen to serve the most recurrent functions that speakers find need to fulfill" (Ford et al., 2014: 122), since both are derived from multi/plurilingual experience and are fairly schematic in nature. This analogy, however, does not do much more than corroborate the validity of HA and is definitely not developed enough to systematically reconstruct LC. In fact, some of the alreadyasked questions, i.e. about the relation between the system and its context(s), perception and conception, linguistic and non-linguistic experience, or generality and specific, become even more relevant. Thus, we suggest that a cognitive linguistic perspective upon LC is adopted since it allows us to move from an unelaborated hyperlinguistic awareness to a more comprehensive framework for re-defining LC.

\section{The schematic commitment of $\mathbf{C L}$}

Cognitive linguistics, embracing the latest findings in complexity science, cognitive psychology, grounded cognition, and intercultural pragmatics, is a broad enterprise which can, nevertheless, be unified through a set of key assumptions, e.g. generality, cognitive, embodied or experiential commitments (Evans, Green, 2006: 4). Schematic structures, such as conceptual archetypes, image schemas or parametric concepts, which are the fundamental constructs of CL, not only fulfill all its promises but also constitute a link between CL and linguistic competence in the CEFR in that hyperlinguistic awareness - an assumed reformulation of LC - and schematic concepts are both superordinate categories. Unlike HA, however, cognitive schemas are not linked solely to plurilingual experience but are taken to permeate cognition at all its levels - from innate abilities to situated conceptualizations. Tracing the recurrence of schematic structures throughout conceptual and linguistic systems interacting with the world of experience, or acting on the schematic commitment, will enable us to re-address the paradoxes characteristic of the way LC is presented in the CEFR.

Cognitive linguists argue that language is not learned thanks to innate, language-specific structures but through general sociocognitive abilities, including pattern-finding skills (Tomasello, 2005), which in turn facilitate the formation of basic sensorimotor schemas. These schemas have been referred to as image schemas, i.e., 
primitive cognitive universals based in genetic traits and representing embodied knowledge of the physical world as sketchy categories, such as FORCE, PATH or UP-DOWN (Johnson, 1987), conceptual archetypes, including "a physical object, an object in a location, an object moving through space, the human body, the human face, a whole, and its parts, [or] a physical container and its contents" (Langacker, 2008: 33-34). While there is a general consensus that schematic concepts are prelinguistic, at least some of them, i.e. spatial primitives (Mandler, Cánovas, 2014), have also been classified as pre-conceptual and thus (near-)universal.

If the conceptual system is founded on schemas, they naturally become its constitutive part and effectively constrain its development. In fact, schematic concepts are necessary for the conceptual system to function effectively. As Z. Kövecses (2015: 32-35), following L. Barsalou (1999), notes, conceptual systems need to be able to represent both immediate and nonimmediate experience in a meaningful way, allow for making inferences and novel conceptualizations and be accessible to a large number of users, i.e. concepts/conceptualizations must be pairable with (linguistic) forms to become symbols. In order to fulfill its tasks, a perceptual and modal conceptual system needs to be embodied, schematic, frame-based, and linguistically coded, and all of these requirements involve schematic structures. For instance, both embodiment and schematic entail the presence of image schemas (Langacker, 1997), while frames are constituted by schematic entities and relations, e.g. PARTICIPANTS, PLACE, OBJECT, SETTING or BE PART OF (Fillmore, 1982).

Schematic structures underlie the conceptual system and are constantly reinforced by our interactions with the world. Thus, all mental representations are composed of perceptual symbols - sensory, motor, affective, introspective, social, and linguistic - derived from multimodal experience and incorporated into simulators, or concepts, which consequently contain a vast amount of knowledge and can produce an indefinite number of context-induced simulations, or meanings (Barsalou, 2016).

While linguistic and non-linguistic perceptual symbols are generally acknowledged as forming simulators, the former is granted a unique position in CL because of their particular relation with schematic structures. To begin with, the Words as Social Tools theory (Borghi, Binkofski, 2014) stipulates that although linguistic experience is captured by simulators in the form of linguistic representations, e.g. acoustic properties or inner speech, and thus linguistic and nonlinguistic perceptual symbols are made to interact within a concept; this interface is based on qualitative differences between the two kinds of symbols. These differences are specified by V. Evans (2016: 6), who claims that the language system attracts two types of representations - rich and schematic. Detailed meanings come directly from the conceptual system, i.e. information encoded in multimodal simulator, while sketchy, or parametric, meanings are "not straightforwardly imageable" and thus less directly linked to the conceptual system. This unobvious link is provided by schematic concepts, i.e. conceptual archetypes, which underlie all grammatical categories as "subjective counterparts of basic aspects of everyday experience (Langacker, 2008: 538), elements of frames, such as SETTING, AGENT, OBJECT or ACTION, which are not only the classic types of slots related to linguistic structures but also "local outputs of the situation-processing architecture [within a frame]" (Barsalou, 2016: 18), or image schemas, e.g. CONTAINMENT or CENTRE-PERIPHERY, which form the schematic meanings of grammatical categories, such as ergative or monotransitive sentence patterns (Talmy, 2000: 87-88).

Schematic constructs are the foundation of inter-related conceptual and linguistic systems and constrain the way we perceive the world and arrange our new experiences. T. Nelhaus (2006) even claims that our situated interactions not only involve existing schemata but may also influence them at the neurological level. Also, individual languages may change basic concepts, but these alterations introduce only

XLinguae, Volume 13 Issue 4, October 2020, ISSN 1337-8384, ISSN 2453-711X 
minor refinements to foundational notions. As J. M. Mandler and C. P. Cánovas (2014: 513) put it, words in different languages, such as Korean and English, may elaborate the CONTAINMENT schema in various ways, but "both languages express containment". All in all, then, schematic structures are largely assumed to be (near)universal. V. Evans (2016: 2), for instance, shows that virtually all languages include a pronoun system that preserves a role for the second person, interrogatives, imperatives, and deontic modality, all of which are "the linguistic resources that seek to influence others" and thus elaborate the FORCE schema. These omnipresent schematic structures are the foundation upon which LC in the CEFR can be reconstructed.

\section{The schematic commitment in re-defining $\mathrm{LC}$}

(Near-)universal schematic meanings, possibly underlain by our speciesspecific ability to generate them (Evans, 2016: 11), are always present in a simulator, but they are not necessarily those conceptualizations that have been conventionalized by a given community. In fact, as author and author (2017: 244) argue, "encoding and decoding schematic content is not easy because neither employing nor discovering the abstract basis of language is simple". Thus, when interacting, we prefer to resort to more readily-available elements of simulators, e.g. "knowledge and beliefs that usually belong to a certain speech community as a result of prior interactions and experience" (Kecskes, 2014: 160). Consequently, schematic, socio-cultural, and pragmatic conceptualizations combine in a simulator (Croft, 2001: 18), and LC becomes closely intertwined with the other communicative competencies in the CEFR as well as with general knowledge and plurilingual/pluricultural proficiencies. An interesting illustration of how those qualitatively different dimensions of a simulator can interact is provided by I. Kecskes (2014: 117) in the form of the following exchange: A) Why don't you sit down? B) Because you didn't tell me to, where person A evokes the schematic/parametric meaning residing in the whole utterance, while person B concentrates on the more detailed/multimodal level of individual words.

The above-mentioned example reinforces not only the claim that LC is integrated with the other competencies in the CEFR, in the same way as linguistic and non-linguistic perceptual symbols are always combined in a simulator, but also the assumption that meanings of individual units, e.g. words, may be less important than meanings of wholes, e.g. sentence patterns. To illustrate this asymmetry, let us consider the verb slice, which can felicitously occur within transitive (He sliced the bread), caused-motion (Pat sliced the carrots into the salad), ditransitive (Pat sliced Chris a piece of pie), way (Emeril sliced and diced his way to stardom), and resultative (Pat sliced the box open) constructions (Goldberg, 2003: 221). To account for the distribution of the verb from the CEFR's perspective on LC, we would have to assume that slice has enough (grammatical) semantic information to combine with as many as five distinct patterns, which simply means that we assemble the utterances from a number of abstract and virtually meaningless categories, processes, classes and relations (cf. Section 2.1). CL's alternative is to expect general-level constructions to be meaningful themselves and hence able to decisively determine the interpretation. For example, in What did Liza buy a child?, six types of meaningful units combine: word, ditransitive, question, subject-auxiliary inversion, VP, and NP constructions (Goldberg, 2003: 221). And while all of them undoubtedly contribute to understanding the expression, it is the meaning of the entire utterance that determines the meanings of its parts rather than the other way round (Croft, 1993).

A non-compositional, top-down approach to LC in which all forms are meaningful, i.e. understood through perceptual symbols, entails that language is a structured inventory of symbolic units, or constructions, i.e. form-meaning pairings of various degrees of complexity and specificity, including morphemes, words, idioms and fully or partially filled general linguistic patterns (Goldberg, 2003: 219). If forms 
(spoken, written, gestured) are always matched with meanings (schematic, sociocultural, pragmatic), then the three classes of competencies distinguished in Section 2 should be changed accordingly. Phonological competence - apparently closest to the CL perspective proposed here - could nevertheless benefit from highlighting the notion of schematic meaning. In this way, phonological proficiency could both remain attached to plurilingual proficiency (through the construct of HA) and become firmly related to LC (through the concept of parametric meaning). Grammatical, orthoepic, and semantic proficiencies should be thoroughly revised and/or abandoned since the first two concentrates on either forms alone or forms combined with no (meaningful) content, while semantic competence formally sanctions abstract (amodal) "meanings" rejected through the schematic commitment. Lexical and orthographic competencies, in turn, should be systematically referred to a variety of meanings (or contexts), including schematic, socio-cultural and pragmatic. Moreover, in the case of lexical competence, two fallacies generated by the formal approach: rules/lists and (regular) core/(irregular) periphery (cf. Section 2.2) need to be re-addressed. In fact, these dilemmas are handled jointly in CL.

To begin with, J. R. Taylor (2002: 541) claims that there is virtually no regularity in language, and hence all constructions/symbolic units are more or less idiomatic, i.e. they are "conventionalized form-meaning relations at varying level of schematicity". On this account, even apparently regular expressions, e.g. Would you like some coffee?, do not emerge as a result of rule application but are formed from the input since, as J. R. Taylor (2002: 540) further argues, it would be unfeasible to assume that whenever we want to ask questions like the one above, we assemble them from component units according to syntactic rules. If, then, idiomaticity is the core of the language, it is the irregular and the idiosyncratic that needs to be studied in order to discover generalizations since, as J. R. Taylor (2002: 558) puts it, "grammar comes to be characterized not in terms of ever more general rules and principles, but as a huge inventory of rather particular facts, interrelated by schemas of varying levels of schematicity."

If rules and other invisible/inaudible elements of LC disappear and all linguistic units are meaningful, the difference between grammatical and lexical competences in the CERF is purely qualitative in that grammar is mostly characterized by parametric meanings while the lexicon, though founded upon cognitive schemas, by socio-cultural and pragmatic elements. Both grammatical and lexical units need to be learned since they involve a considerable degree of unpredictability. Rule-like constructions abstracted from language use and supported by (near-)universal schemas co-occur with lower-level generalizations in the language system whose core is constituted by "routine formulas, fixed and semi-fixed expressions, idioms, and frozen collocations" (Tomasello, 2005: 9), which at once show native-like mastery and hinder plurilingual (lingua franca) communication (Seidlhofer, 2004: 220). This paradox is explained by I. Kecskes (2016: 15), who notes that language learners, apparently driven by the need to sound idiomatic and hence natural, will always "make an effort in their own way to keep the original rules of the game. This means that they try to use formulas that appear to be the best means to express their immediate communicative goals [and] create new formulas if the need arises". (Kecskes, 2016: 15). Thus, rather than promote high lexical accuracy so that confusion and incorrect word choice does not obstruct communication (Council of Europe, 2018: 134), Vocabulary control should take imprecision and a mix of influences as a norm.

Placing intelligibility over accuracy means that schematic meanings come to the fore again. Clearly, in order to understand "novel idioms" such as, "it almost skips from my thoughts, you are not very rich in communication, [or] take a school" (Kecskes, 2016: 15), LC must be developed beyond the specific conventions of L2

XLinguae, Volume 13 Issue 4, October 2020, ISSN 1337-8384, ISSN 2453-711X 
and towards the schematic frames of (near)-universal nature. Likewise, to understand that Tell me about it! in fact, means the opposite (Kecskes, 2014: 99), the schematic element, conveyed via the intonation pattern, or an "overt closed-class element" (Talmy, 2000: 23), needs to be mastered. All in all, then, schematic meanings may turn out to be the foundation upon which effective communication is built.

Schematic meanings permeate cognition and, expectedly, manifest themselves throughout general, communicative, and plurilingual/pluricultural competences in the CEFR as (near-)universal elements of knowledge about the physical world, parametric meanings, and hyperlinguistic awareness, respectively. They tighten the links between communicative language competences since sociolinguistic and pragmatic meanings come together in a concept with linguistic meanings just as non-linguistic and linguistic perceptual symbols do. While not irrelevant for re-shaping LC in the Framework, these observations are just the background against which linguistic competence - our primary concern - should be re-interpreted.

The main changes to $\mathrm{LC}$, resulting from the $\mathrm{CL}$ approach and the schematicity commitment adopted, naturally emerge from our discussion so far and can be summarized at general and specific levels. From the broadest perspective, LC can be defined as an ability to process constructions, or symbolic units, indispensable for effective communication. This overall characterization results in a number of particular statements:

- only naturally-occurring units and generalizations over them are elements of LC, i.e. symbolic units

- $\quad$ symbolic units - form-meaning pairings - are structured according to their level of schematicity,

- forms are written, spoken or gestured,

- meanings encompass schematic, socio-cultural, and pragmatic elements,

- the ability to process schematic content is crucial for developing LC,

- $\quad$ irregularity is the central feature of the language system,

- $\quad$ LC is developed through learning,

- wholes rather than parts and lists rather than rules are the basic constructs characterizing LC.

How much, if any, influence the above guidelines will have on re-constructing LC in the CEFR is a matter of speculation, but what should not be doubted is that LC needs to be re-formulated to be tenable. Perhaps a good starting point would be to expand on what has already been revamped in the Framework, i.e. the notion of phonological competence, and highlight its key aspects: meaningfulness of forms and intelligibility within the other sub-competencies of LC. Moreover, if schematic meanings, as already suggested above, were to be incorporated within phonological descriptors, particularly with reference to prosodic features, a link could be established between phonology and grammar in the CEFR since both instantiate parametric meanings. Another question to consider within phonological competence is whether skills related to the articulation of sounds and those connected with exploiting prosodic features should be treated on a par, as currently implied by the Framework (Council of Europe, 2018: 136), or whether the mastery of wholes, e.g. intonation patterns, should perhaps be more prominent than competences related to individual sounds.

Apart from, or as well as, elaborating on phonological competence, LC could be easily made more coherent if the (often unrelated) theoretical underpinnings currently attached, albeit unproportionally, to individual sub-competencies, were replaced with a consistent, possibly inspired by CL, the background to $L C$ as a whole.

Finally, certain themes, so to speak, could be made recurrent throughout linguistic competence to facilitate its integrity. These key notions, as already partly suggested, could encompass symbolic units/constructions, meaning(s), intelligibility, 
schematicity, learning/memorization, idiomaticity. Clearly, most of them are already present in the Framework, and perhaps what is needed first of all is simply a shift of focus.

\section{Conclusion}

Linguistic competence in the CEFR is not defined in a consistent way and thus does not constitute a reliable notion. This situation is far from felicitous in the case of a document whose aim is to facilitate language learning and teaching and in fact, function as a "tool for coherent, transparent and effective plurilingual education" (Council of Europe, 2018: 25). At the same time, though, this status quo is not unexpected since the Framework attempts to bridge (at least) two paradigms: (socio) cognitive, ${ }^{2}$ characteristic of the 2001 document, and socioconstructive, which emanates from the 2018 companion volume. Consequently, certain concepts are still (partly) attached to the original vision, others overlap, and still others have been thoroughly re-defined. LC illustrates all these tendencies.

Inspired by the notion of hyperlinguistic awareness, we suggested that the schematic commitment of cognitive linguistics could become a foundation upon which to re-structure LC. But in fact, there were also other stimuli, and the current proposal owes much to four sources.

Firstly, there is an undisputable relation to D. Newby's (2011: 19) idea of schematic competence, "which should be incorporated in any model which aims at describing general competence". In our view, however, schematic capabilities, though vital for all, including general competencies, are most advanced in and particularly relevant for linguistic (grammatical) and plurilingual proficiencies.

Secondly, A. M. Pirc's (2013) constructionist approach to ELF communication and her focus on learning, context-specific emergence, and grammar in general, with particular emphasis, though, on W. Croft's (2001) construction grammar, clearly resonate in our proposal, which is, nevertheless, much closer to $\mathrm{R}$. Langacker's $(1987 ; 2008)$ vision of grammar.

Thirdly, D. Larsen-Freeman's (2018: 58), discussing current trends in theories of language development, points out that any framework aiming at combining social and cognitive strands should do so in a way that involves "embodied cognition". Our cognitive linguistics perspective, with its focus on schematicity, clearly meets this requirement.

Finally, there is the CEFR itself, where traces of both schematicity and embodiment commitments can be found. The former is instantiated by formal, content, interactional and transactional schemata (Council of Europe, 2018: 67, 138), while the latter is extensively present in the form of the ECML's ProSign Project (Council of Europe, 2018: 145). Based on spatial and diagrammatical competences and involving facial expression, body, head, and mimics as well as hand and arm movement, sign languages are par excellence embodied systems. Perhaps then the Framework could move a step further and integrate those, and possibly other, alreadyavailable elements of cognitive linguistics into its characterization of further proficiencies. Our proposal has been created with a view to assisting in this process.

\footnotetext{
${ }^{2}$ The parantheses are used to indicate that the CEFR (Council of Europe, 2001) uses the term in an asymmetrical way, with apparently more emphasis on the individual than the collective, as evidenced by the way LC is defined,and thus to distinguish it from a fully balanced and integrated sociocognitive approach (Larsen-Freeman, 2018).
}

XLinguae, Volume 13 Issue 4, October 2020, ISSN 1337-8384, ISSN 2453-711X 


\section{Bibliographic references}

BARSALOU, L. W. 2009. Simulation, situated conceptualization, and prediction. In: Philosophical Transactions of the Royal Society of London: Biological Sciences, vol. 364, n. 1521, pp. 1281-1289. ISSN 1471-2970.

BARSALOU, L. W. 2016. Situated conceptualization: Theory and application. In: Coello, Y. - Fischer, M. H. (eds.): Foundations of embodied cognition. East Sussex, UK: Psychology Press. pp. 1-17. ISSN 1747-0226.

BORGHI, A. M. - BINKOFSKI, F. 2014. Words as Social Tools: An Embodied View on Abstract Concepts. Berlin; New York, NY: Springer. ISBN 978-1-4614-9539-0.

COUNCIL OF EUROPE. 2001. The Common European Framework of Reference for Languages: Learning, Teaching Assessment. Strasbourg: Council of Europe. ISBN is not present.

COUNCIL OF EUROPE. 2018. The Common European Framework of Reference for Languages: Learning, Teaching Assessment. Companion Volume with New Descriptors. Strasbourg: Council of Europe. ISBN is not present.

CROFT, W. 1993. The role of domains in the interpretation of metaphors and metonymies. In: Cognitive Linguistics, vol. 4, n. 4, pp. 335-370. ISSN 0936-5907 (print) 1613-3641 (online).

CROFT, W. 2001. Radical Construction Grammar: Syntactic Theory in Typological Perspective. Oxford: Oxford University Press. ISBN 0198299540.

EVANS, V. 2016. Design Features for Linguistically-Mediated Meaning Construction: The Relative Roles of the Linguistic and Conceptual Systems in Subserving the Ideational Function of Language. In: Frontiers in Psychology, vol 7, n. 156, pp. 102-113. ISSN 1664-1078.

EVANS, V. - GREEN. M. 2006. Cognitive Linguistics: An Introduction. Edinburgh: Edinburgh University Press. ISBN 0748618317.

FILLMORE, C. 1982. Frame Semantics. In: The Linguistic Society of Korea (ed.): Linguistics in the Morning Calm. Seoul: Hanshin Publishing. pp. 111-137. ISBN is not present.

FORD, C. - FOX, B. - THOMPSON, S. 2014. Social interaction and grammar. In: Tomasello, M. (ed.): The new psychology of language. Hove: Psychology Press. pp. 119-144. ISBN 10: 1848725949.

FULCHER, G. 2004. Deluded by artifices? The Common European Framework and harmonization. In: Language Assessment Quarterly, vol. 1, n. 4, pp. 253-26. ISSN 1543-4303.

GOLDBERG, A. 2003. Constructions: a new theoretical approach to language. In: Trends in Cognitive Sciences, vol. 7, n. 5, pp. 219-224. ISSN 1364-6613 (print) 1879$307 \mathrm{X}$ (online).

JOHNSON, M. 1987. The Body in the Mind: the Bodily Basis of Meaning, Imagination, and Reason. Chicago: The University of Chicago Press. ISBN 9780226403182.

KECSKES, I. 2014. Intercultural Pragmatics. Oxford: Oxford University Press. ISBN 978-0-19-989265-5.

KECSKES, I. 2016. Bilingual Pragmatic Competence. In: Reif, M. - Robinson, J. A. (eds.): Cognitive Perspectives on Bilingualism. Berlin: Mouton de Gruyter. pp. 3664. ISBN 978-1-61451-419-0.

KÖVECSES, Z. 2015. Where Metaphors Come From. Oxford: Oxford University Press. ISBN 978-01-9022-486-8.

LANGACKER, R. W. 1987. Foundations of cognitive grammar. Vol.1: Theoretical prerequisites. Stanford: Stanford University Press. ISBN 13: 978-0804738514.

LANGACKER, R. W. 1997. Generics and Habituals. In: Athanasiadou, A. - Dirven, R. (eds.): On Conditionals Again. Amsterdam and Philadelphia: John Benjamins, pp. 191-222. ISBN 9789027275981. 
LANGACKER, R. W. 2008. Cognitive Grammar: a basic introduction. Oxford: Oxford University Press. ISBN 13: 978-0195331967.

LARSEN-FREEMAN, D. 2017. Just Learning. In: Language Teaching, vol. 50, n. 3, pp. 425-437. ISSN 0261-4448 (print) 1475-3049 (online).

LARSEN-FREEMAN, D. 2018. Looking ahead: Future directions in, and future research into, second language acquisition. In: Foreign Language Annals, vol. 51, n. 1, pp. 55-72. ISSN 1944-9720.

MANDLER, J. M. - CANOVAS, C. P. 2014. On defining image schemas. In: Language and Cognition, vol. 6, n. 5, pp. 510-532. ISSN 1866-9808 (print) 1866-9859 (online).

NEWBY, D. 2011. Competence and performance in learning and teaching: theories and practices. In: Selected papers on theoretical and applied linguistics, vol. 19, pp. 15-32. E-ISSN 2529-1114.

NELHAUS, T. 2006. Performance strategies, image schemas, and communication frameworks. In: McConachie, B. - Hart, F. E. (eds.): Performance and Cognition: Theatre Studies and the Cognitive Turn. London: Routledge. pp. 76 94. ISBN 9780203966563.

PIRC, A.M. 2013. Construction Grammar and Non-native Discourse. In: Theory \& Practice in Language Studies, vol. 6, n. 1, pp. 55-73. E-ISSN 1805-0859.

SEIDLHOFER, B. 2004. Research Perspectives on Teaching English as a Lingua Franca. In: Annual Review of Applied Linguistics, vol. 24, n. 1, pp. 209-239. ISSN 02671905.

STRUGIELSKA, A. - PIĄTKOWSKA, K. 2017. A plea for a socio-cognitive perspective on the language-culture-cognition nexus in educational approaches to intercultural communicative competence. In: Review of Cognitive Linguistics, vol. 15, n. 1, pp. 224-252. ISSN 1877-9751 (print) 1877-976X (online).

TALMY, L. 2000. Toward a cognitive semantics. Cambridge: MIT Press. ISBN: 9780262201209573.

TAYLOR, J. R. 2002. Cognitive Grammar. In: Journal of Child Language, vol. 31, n. 2, pp. 421-424. ISSN 0305-0009 (print) 1469-7602 (online).

TAYLOR, J. R. 2014. Cognitive Linguistics. In: Allan, K. (ed.): The Routledge Handbook of Linguistics, pp. 455-469. ISBN 9780415832571.

TOMASELLO, M. 2005. Constructing a Language: A Usage-Based Theory of Language Acquisition. Harvard: Harvard University Press. ISBN 9780674017641.

VINCENT, L. 2004. Compétence communicative et savoirs culturels en didactique des langues étrangères: analyse critique du Cadre européen commun de référence pour les langues. In: Greenfield, J. (ed.): Proceedings of the symposium Ensino das Línguas Estrangeiras: Estratégias Politicas e Educativas (13-15 December 2001). Porto: Faculdade de Letras da Universidad do Porto. pp. 41-50. ISBN, 972-9350-75-2. WEIR, C. J. 2005. Limitations of the Common European Framework for developing comparable examinations and tests. In: Language Testing, vol. 22, pp. 281-300. ISSN 02655322 .

Words: 6560

Characters: 45927 (25,52 standard pages)

Ariadna Strugielska

Katarzyna Piątkowska

Department of English Language and Applied Linguistics

Nicolaus Copernicus University

Bojarskiego 1, 87-100 Toruń

Poland

ariadna.Strugielska@umk.pl,kapia@umk.pl

XLinguae, Volume 13 Issue 4, October 2020, ISSN 1337-8384, ISSN 2453-711X 